\title{
Mechanisms of gastrointestinal allergic disorders
}

\author{
Nurit P. Azouz and Marc E. Rothenberg \\ Division of Allergy and Immunology, Department of Pediatrics, Cincinnati Children's Hospital Medical Center, University of Cincinnati College of Medicine, Cincinnati, Ohio, USA.
}

\begin{abstract}
Gastrointestinal (GI) allergic disease is an umbrella term used to describe a variety of adverse, food antigen-driven, immunemediated diseases. Although these diseases vary mechanistically, common elements include a breakdown of immunologic tolerance, a biased type 2 immune response, and an impaired mucosal barrier. These pathways are influenced by diverse factors such as diet, infections, exposure to antibiotics and chemicals, GI microbiome composition, and genetic and epigenetic elements. Early childhood has emerged as a critical period when these factors have a dramatic impact on shaping the immune system and therefore triggering or protecting against the onset of $\mathrm{Gl}$ allergic diseases. In this Review, we will discuss the latest findings on the molecular and cellular mechanisms that govern $\mathrm{Gl}$ allergic diseases and how these findings have set the stage for emerging preventative and treatment strategies.
\end{abstract}

\section{Introduction}

Adverse reactions to food involve both immune-mediated and non-immune-mediated responses. Among these responses, there has been increasing attention to gastrointestinal (GI) allergic diseases, a spectrum of disorders classified by IgE-mediated, nonIgE-mediated, and mixed IgE-mediated and non-IgE-mediated mechanisms. Loss of tolerance to harmless food antigens results in initiation of immune hypersensitivity, and failure to terminate immune responses leads to chronicity $(1,2)$.

Basic and translational studies have uncovered several common pathways in GI allergic diseases. First, although not formally demonstrated for each of these diseases, a breakdown of immunologic tolerance appears to be a key feature. Loss of tolerance can stem from a number of mechanisms, including alterations in the immune surveillance system (e.g., dysregulation of antigen processing and change in Treg function). Second, a biased type 2 immune response is also a key factor in disease onset, manifestations, and maintenance. Several allergic GI diseases involve imbalanced Th2 effector cell responses compared with responses of other T cell types (i.e., Treg, Th1, Th17) as well as increased Th2 cytokine production. The Th2 response increases IgE and mast cell, basophil, and eosinophil production and activation. Third, an impaired epithelial barrier is an apparent mechanism, resulting in increasing encounters of food antigens with immune cells, priming a break in immune tolerance and initiation of epithelial innate immune responses that further prime for Th2 responses.

Conflict of interest: MER is a consultant for PulmOne, Spoon Guru, ClostraBio, Celgene, Shire, AstraZeneca, GlaxoSmithKline, Allakos, Adare, Regeneron, and Novartis; has an equity interest in the first three listed companies and Immune Pharmaceuticals; and has received royalties from Teva Pharmaceuticals (for reslizumab) and UpToDate. NPA and MER are inventors on a pending US patent application $(62 / 126,814)$ submitted by Cincinnati Children's Hospital Medical Center that covers serine protease inhibitors for the treatment of eosinophilic esophagitis. MER is an inventor on a patent on the eosinophilic esophagitis diagnostic panel, which is owned by Cincinnati Children's Hospital Medical Center (US patent 9,928,34 B2).

Copyright: ๔ 2019 The American Society for Clinical Investigation

Reference information: / Clin Invest. 2019;129(4):1419-1430.

https://doi.org/10.1172/JCI124604.
Finally, cooperating environmental and genetic factors influence these pathways and therefore promote or protect against allergic GI diseases.

\section{Immunologic basis of GI allergic disease}

Cells and loss of tolerance. Allergic diseases involve the interplay of a constellation of cells, including mast cells, basophils, eosinophils, lymphocytes, and constitutive tissue cells such as epithelial cells and antigen-presenting cells. These cells and their orchestrated interactions are normally involved in protective immunity to certain pathogens, typically parasites (3). A summary of the immunologic basis of food allergic subtypes is presented in Table 1.

Under healthy homeostatic conditions, remaining unresponsive to food is a primary objective of the immune system. Such immune tolerance is generated by relocation of antigen from the gut lumen to the lamina propria by specialized M cells, myeloid cells, and goblet cells. Goblet cells have a key role in the development of intestinal tolerance, serving as a passage for antigen transit from the lumen to tolerance-inducing dendritic cells (DCs) $(4,5)$. The intestine's mucus layer not only provides a physical barrier but permits tolerance-inducing DCs to sample bacteria (6). Following transmission of antigen to the lymphoid tissue and subsequent antigen presentation, tolerogenic $\mathrm{T}$ cells return to the intestine (2). Tregs require the transcription factor forkhead box P3 (FOXP3) and secrete IL-10 and TGF- $\beta$. IL-10 is a key regulatory cytokine that is also produced by DCs and a number of other T cells. IL-10 terminates allergen-specific Th2 responses and induces Treg differentiation (7). Tolerance-regulating Tregs have an essential role in downregulating Th2 cells and inhibiting IgE-mediated mast cell activation, thus preventing inflammatory responses and maintaining physiologic homeostasis at mucosal surfaces (8). Interestingly, the chronic allergic disease eosinophilic esophagitis (EoE) is characterized by increased TGF- $\beta$. TGF- $\beta$ is produced by many cell types in the esophagus, including eosinophils and mast cells, and promotes tissue fibrosis, epithelial-mesenchymal transition, and smooth muscle contraction; therefore, TGF- $\beta$ likely has a dual pathogenic and immune-regulatory role in EoE rather than a sim- 
ple protective role (9). The esophagus of EoE patients contains persistent Tregs $(10,11)$; whether these Tregs actively produce TGF- $\beta$ and whether they possess a protective or proinflammatory role require further investigation.

It is interesting that breast milk contains immunoregulatory mediators including TGF- $\beta$ and that TGF- $\beta$ supplementation induces tolerance in a murine model of food allergy (12). Following epicutaneous sensitization and oral challenge in pregnant mice, the offspring evidenced attenuation of food anaphylaxis, specific IgE production, and intestinal mast cell numbers. This mechanism is mediated by induction of allergen-specific Tregs and transfer of maternal IgG complexes with the antigen in breast milk by the neonatal crystallizable fragment receptor, FcRN, expressed by DCs (13). Interestingly, human breast milk containing IgG-allergen immune complexes induces tolerance in humanized FcRN mice (13).

Barrier. Atopic diseases tend to occur in a chronological sequence termed the atopic march, in which the initial manifestation of atopic disease in early childhood is often in the skin (i.e., atopic dermatitis $[\mathrm{AD}]$ ), followed by the staggered development of food anaphylaxis, EoE, allergic rhinitis, and allergic asthma $(2,14)$. Support for this theory is derived from the finding that a defective skin barrier is an established risk factor for food anaphylaxis and EoE $(15,16)$. Several mouse studies have shown that epicutaneous exposure to allergens causes allergic sensitization, IgE production, Th2 responses, and food anaphylaxis (17-19). Impaired skin barrier, as measured by transepidermal water loss, correlates with the development of food anaphylaxis at the age of 2 years (20).

High-throughput approaches including whole-transcriptome and whole-exome sequencing and genome-wide association studies (GWAS) have revealed that impaired barrier influences the development of GI allergic diseases. First, loss-of-function mutations in the epidermal barrier gene $F L G$ (encoding filaggrin) increase the risk for $\mathrm{AD}$, peanut sensitization, peanut allergy, and EoE $(21,22)$. Filaggrin is a structural protein with key roles in skin homeostasis, including regulation of the physical strength of the epithelium, barrier function, hydration, $\mathrm{pH}$, and antimicrobial protection (23). Up to half of European AD patients have loss-offunction genetic variants in $F L G$, which is the most significant known genetic risk factor for $\mathrm{AD}$ (23). Second, patients with EoE exhibit a marked decrease in the esophageal cadherin desmoglein-1 (DSG1) compared with control individuals. In vitro, loss of DSG1 in esophageal epithelial cells causes impaired epithelial barrier, indicating that DSG1 may have a key role in epithelial integrity (24-26). Mutations that decrease DSG1 expression stimulate production of Th2 cytokines, including thymic stromal lymphopoietin (TSLP), and associate with severe atopy, including food anaphylaxis, EoE, and metabolic wasting known as severe dermatitis, multiple allergies, and metabolic wasting (SAM) syndrome (discussed in the next section) (27). Third, the cysteine protease calpain-14 (CAPN14) also mediates esophageal barrier function and contributes to the pathology of EoE. Overexpression of CAPN14 in esophageal epithelial cells decreases DSG1 expression and impaired barrier function. CAPN14 is induced by IL-13, and silencing of CAPN14 prevents IL-13-mediated DSG1 loss. Whether CAPN14 directly cleaves DSG1 is yet unknown (28). Fourth, loss of expression of the serine protease inhibitor SPINK7, as occurs in EoE, is sufficient to induce epithelial barrier impair- ment, including increased proteolytic activity with inflammatory consequences (29). Additional examples of dysregulated barrier genes are found among the epidermal differentiation complex (EDC) genes clustered on chromosome 1q21, including the genes FLG and IVL, which are markedly decreased in EoE (30).

The above data substantiate that impaired barrier function can enhance the development of the atopic response, probably via two mechanisms: (a) penetration of the tissue by unwanted antigens that subsequently encounter antigen-presenting cells, and (b) epithelial "damage sensing," whereby pathogenic insults activate protease-activated receptors (PARs) and pattern recognition receptors (including TLRs) on epithelial cells (31-33). This activation deploys innate immune responses. For example, double-stranded RNAs and proteolytic allergens upregulate TLR-mediated and/or PAR2-mediated TSLP induction in keratinocytes $(34,35)$.

Several studies reveal that barrier proteins have the potential to modulate immune reactions. For example, SPINK7 inhibits the serine protease urokinase-type plasminogen activator (uPA), which can activate eosinophils by cleaving UPAR expressed on their cell surface, which likely occurs in EoE (29). A summary of barrier regulatory molecules and their regulation in an allergic response is illustrated in Figure 1.

\section{Heritability of GI allergic disorders}

Studies on cohorts of twins and triplets with a confirmed GI allergic disorder in at least one sibling estimate that the heritability is typically very high $(>50 \%)$ regardless of the type of GI allergic disease. The genetic component's contribution to this heritability is variable between specific diseases $(36,37)$. In EoE, heritability is high (with sibling risk ratios approaching 50-fold risk), but a twin study revealed that genetics only contribute about 15\% (38). This is most highlighted by the 10-fold higher rate of concordance between dizygotic twins than between non-twin siblings, implicating early-life exposures as the main environmental driver $(38,39)$.

Common genetic variant analysis of food allergy. GWAS focusing on common genetic variants $(>5 \%$ prevalence in the general population) have identified several genes involved in barrier function that associate with susceptibility to food anaphylaxis $(21,40)$. For instance, genetic variants in FLG associate with food anaphylaxis and EoE susceptibility $(22,40)$, and downregulation of FLG directly contributes to EoE by contributing to impaired esophageal epithelial barrier function $(29,30,41)$.

Recently, the SERPINB gene cluster on chromosome 18q21.3 was identified as a novel locus associated with food anaphylaxis (21). In addition, whole-exome sequencing analysis of EoE patients identified rare damaging mutations in the SERPINB3 gene (42), suggesting critical involvement of this family of protease inhibitors in the pathogenesis of allergic diseases. Because these proteins are mainly localized to the epithelium and function as protease inhibitors, they likely regulate barrier integrity.

EoE's strong genetic association with variants at 2 p23 helped mechanistically explain the tissue specificity of this disease. This locus contains the CAPN14 gene, whose esophagus-specific expression and involvement in EoE are discussed above (22, 28, 43, 44).

Other variants emphasize type 2-skewed pathways in the onset of food allergic disorders. The first evidence was the genetic linkage of the Th2 cytokine cluster at 5q31-33 with serum 
Table 1. Classifications of GI allergic diseases and their mechanism

\begin{tabular}{|c|c|c|c|}
\hline & Disease & Antigen & Mechanism \\
\hline \multirow[t]{3}{*}{$\begin{array}{l}\text { IgE-mediated } \\
\text { food allergy }\end{array}$} & Food anaphylaxis & $\begin{array}{l}\text { Milk, egg, wheat, fish/shellfish, } \\
\text { peanut/tree nuts, beef, soy, chicken }\end{array}$ & $\begin{array}{l}\text { - Increased Th2 cell differentiation and decreased Tregs } \\
\text { - Antigen encounter promotes secretion of cytokines in the type } 2 \text { family } \\
\text { (e.g., IL-4, IL- 5, IL-9, and IL-13) by Th2 cells } \\
\text { - Stimulated B cell class switch to IgE } \\
\text { - IgE binds to FcERI receptor on mast cells } \\
\text { - Food antigens induce cross-linking of mast cell-bound IgE molecules } \\
\text { - Mast cell degranulation with release of histamine and inflammatory mediators } \\
\text { including proteases, de novo production of lipid metabolites of arachidonic acid, } \\
\text { and de novo production of cytokines (IL-4, IL-13) }(1,3)\end{array}$ \\
\hline & Oral allergy syndrome & Pollen-derived epitopes & Cross-reactive with fruit- or vegetable-protein epitopes \\
\hline & Red meat allergy & $\begin{array}{l}\text { Carbohydrate epitope } \alpha \text {-gal } \\
\text { found in red meat }\end{array}$ & Antigens transmitted in the saliva of ticks that have fed on mammals (2) \\
\hline
\end{tabular}

lgE-mediated and non-lgE-mediated (mixed) food allergy
EGIDs such as EoE

Milk, egg, wheat, fish/shellfish, peanut/tree nuts, soy

- Increased exposure to allergen and encounter with antigen-presenting cells, which lead to break of immune tolerance

- Innate response characterized by epithelial production of IL-1, IL-25, GM-CSF, IL-33, and TSLP, which promote Th2 cell recruitment and activation

- Increased IL-13 production (11, 174)

- IL-13 promotes eotaxin-3 production from epithelial cells, which recruits eosinophils $(174,175)$

- IL-13 promotes CAPN14 expression to promote esophageal epithelial barrier impairment (28)

- Decreased SPINK7 expression promotes esophageal epithelial barrier impairment (29)

- Eosinophilia and tissue damage (175)

\begin{tabular}{|c|c|c|c|}
\hline \multirow{4}{*}{$\begin{array}{l}\text { Non-IgE-mediated } \\
\text { food allergy }\end{array}$} & $\begin{array}{l}\text { Food protein-induced } \\
\text { enterocolitis syndrome }\end{array}$ & Milk, soy, rice, oat, egg & $\begin{array}{l}\text { Preliminary evidence of involvement of neutrophils, NK cells, monocytes and } \\
\text { eosinophils, lack of lgG4, and intestinal permeability in disease propagation } \\
\text { (177-180) }\end{array}$ \\
\hline & $\begin{array}{l}\text { Food protein-induced } \\
\text { proctocolitis }\end{array}$ & Milk, soy, wheat, egg & Preliminary evidence of eosinophilic inflammation $(177,180)$ \\
\hline & Food protein enteropathy & Milk, soy, wheat, egg & Preliminary evidence of allergen-specific suppressor CD8+ T cells (180) \\
\hline & Celiac disease & $\begin{array}{l}\text { Cliadin peptides } \\
\text { (found in gluten) }\end{array}$ & $\begin{array}{l}\text { - TGM2 induces gluten peptide deamidation to increase affinity to HLA-DQ, which } \\
\text { presents these peptides to CD4 }{ }^{+} \text {Tcells } \\
\text { - Proinflammatory T cells promote intestinal damage } \\
\text { - Disease-specific B cells produce autoantibodies against self-TCM2 and } \\
\text { deamidated gluten peptides } \\
\text { - HLA class II genes HLA-DO2 and HLA-D08 susceptibility (180-182) }\end{array}$ \\
\hline
\end{tabular}

GI allergic disorders are classified by either IgE-mediated, non-IgE-mediated, or mixed IgE-mediated and non-IgE-mediated mechanisms. Loss of tolerance, resulting in initiation of immune hypersensitivity to harmless food antigens, and failure to terminate these responses, lead to chronicity of these responses. The food antigens involved in, and the mechanisms of, these diseases are summarized (1-3, 28, 29, 155, 174-187). $\alpha$-gal, galactose- $\alpha-1,3-$ galactose; TGM2, transglutaminase 2 .

IgE levels (45). Later studies associated this locus with EoE (46), Crohn's disease (47), psoriasis (48), eczema (49), and food anaphylaxis (21). The lead SNP at this locus, rs11949166, is located between $I L 4$ and the kinesin family member 3a gene (KIF3A), and a second, independent association is in the RAD5O/IL13 region, which also contains the well-known IL13 coding variant (IL-13 R130Q) (21, 50-52). Consistent with these data, a gainof-function mutation in IL4RA associates with atopy (52).

The 5q22 locus, encompassing TSLP, is associated with a number of allergic diseases, including EoE, asthma, allergic rhinitis, and $\operatorname{AD}(53,54)$. Food anaphylaxis has not been linked to this region, highlighting its distinct mechanisms, as depicted in Table 1.

Other genetic variants might be linked to the breakdown of tolerance through regulation of antigen presentation; for exam- ple, the 11q13 locus encoding EMSY and LRRC32 (22, 55-58) is associated with food anaphylaxis, EoE (59), AD (60), asthma (61), allergic sensitization (62), inflammatory bowel disease, and allergic rhinitis (63). EMSY is a transcription regulator also involved in intracellular signaling (56). LRRC32 is a leucine-rich repeat molecule expressed on the surface of Tregs that binds to TGF- $\beta$ and promotes its processing. The association suggests that altered expression of EMSY and LRR32 can potentially contribute to breakdown of immune tolerance (64).

$H L A-D Q$ and $H L A-D R$, encoding class II HLA molecules, are also suggested to be involved in food anaphylaxis by regulating immune tolerance (65). Antigen-presenting cells induce immune tolerance by presenting peptides to T cells via class II MHC molecules, such as HLA-DQ and HLA-DR. Two SNPs on the HLA 


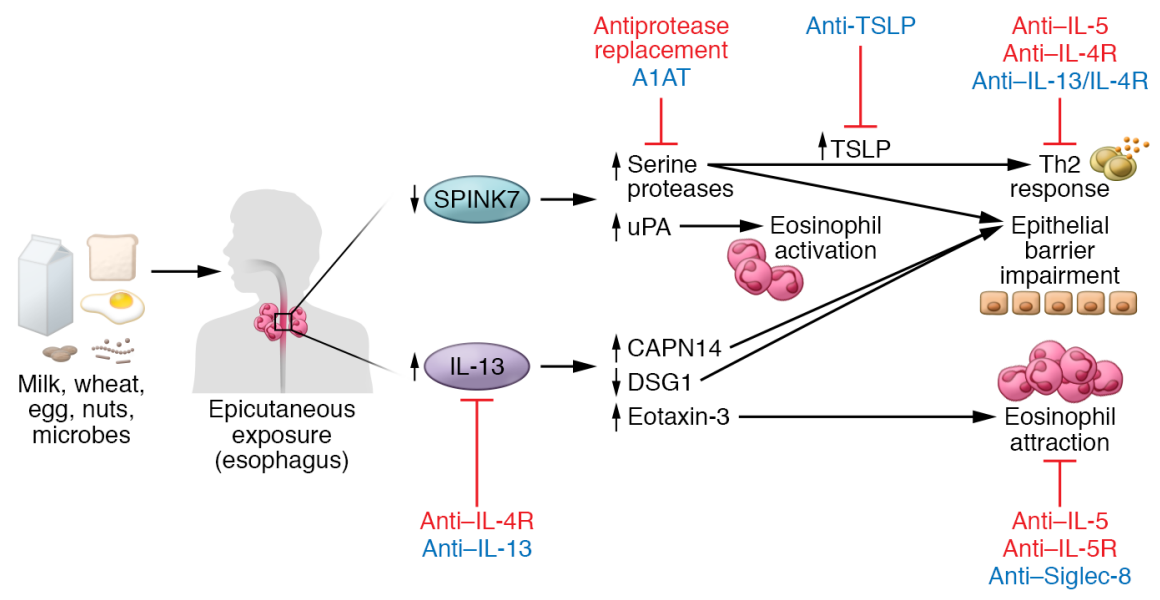

Figure 1. The regulation of epithelial barrier function in EoE. Esophageal allergic responses to food antigens are driven by barrier impairment. Decreases in the esophageal levels of the serine protease SPINK7 lead to increased serine protease activity, which impairs epithelial barrier function and in turn causes innate epithelial proinflammatory responses, including TSLP production. TSLP promotes Th2 responses. This reaction can be controlled by anti-TSLP, anti-IL-13, and/or anti-IL-4R antibodies. In addition, loss of SPINK7 promotes increased esophageal UPA activity that activates eosinophils. Antiprotease replacement of SPINK7, such as A1AT delivery, could potentially restore these pathways. Increased IL-13 promotes epithelial cells to produce eotaxin-3 that attracts eosinophils to the esophagus.

Anti-IL-5, anti-IL-5R, and anti-Siglec-8 therapy reduce and/or eliminate eosinophils. IL-13 also induces decreased expression of the desmosomal protein DSC1, thereby impairing the epithelial barrier, as well as increased expression of the cysteine protease CAPN14, which also impairs the epithelial barrier. Therapeutic reagents that are FDA approved or in clinical trials are shown in red and blue, respectively. region (71). Moreover, an increase in peanut sensitization and allergy risk was seen in children with FLG loss-of-function mutations exposed to high levels of peanut allergens in household dust (72).

Mendelian disorders inform GI allergic disease etiology. Several monogenic disorders associated with GI allergy result from mutations in barrier genes (e.g., those that encode desmosomal junction proteins and the serine protease inhibitor SPINK5. SPINK5 loss of function results in a rare autosomal recessive disorder termed Netherton syndrome (NS) that is characterized by defective skin cornification and Th2-skewed immune alterations (73). Loss of functional SPINK5 unleashes uncontrolled serine protease activities that promote corneodesmosome degradation and excess corneocyte desquamation, resulting in skin barrier dysfunction. NS patients develop a severe atopy syndrome involving progressive increases in serum IgE levels, hypereosinophilia, AD, and EoE. Common SNPs in the SPINK5 locus are associated with $\mathrm{AD}$ severity and with food anaphylaxis (74). Generalizabil-

locus on chromosome 6 significantly associate with peanut-driven allergy but not egg or cow milk allergies (65).

A recently discovered locus at $16 \mathrm{p} 13$, a region encoding the CLEC16A, DEXI, and CITTA genes, was genetically associated with EoE (59). CITTA regulates the expression of class I and II MHC genes that are important in immune tolerance $(66,67)$. Variants in CLEC16A associate with IgA deficiency (68). IgA is involved in mucosal immunity, development of tolerance, and protection against infection; IgA deficiency coexists with autoimmune diseases and allergies (69). DEXI has unknown function, but polymorphism in this gene is associated with autoimmunity (70).

Because many identified variants overlap between several atopic diseases, with the exception of CAPN14, they have poor specificity as biomarkers of allergic diseases. In addition, in allergic disorders with low prevalence rates, such as EoE (1 in 2000), even individuals carrying risk variants that increase the disorder's odds ratio (OR) 2-fold possess relatively low risk of developing the disease.

Considering the combinatorial effect, having two or more risk variants at different loci for disease susceptibility is likely to be important. Martin et al. presented evidence of interaction between SNPs at IL4 and TSLP such that TSLP risk variants most strongly associate with EoE when the IL4 risk variant is present (43). Another genetic interaction is observed between variants in TSLP and the UPA-encoding gene, PLAU, in EoE (29).

Gene-environment interactions. Environmental factors can specifically modify disease risk in genetically susceptible subjects. For example, breastfeeding reduces EoE risk in individuals with the rs6736278 susceptibility gene variant in CAPN14, and neonatal intensive care unit admission significantly increases EoE risk in individuals carrying a specific riskallele in the $L O C 283710 / K L F 13$ ity of these rare Mendelian disease observations is evidenced by the finding that both SPINK5 and SPINK7 expression is decreased in the esophagus of EoE patients compared with control individuals $(29,75-77)$ and that these are generally acquired events rather than a consequence of genetic loss of function. Mutations in CDSN (encoding corneodesmosin) cause peeling skin disease, with features similar to those of NS, including multiple food allergies (78). Another monogenic disorder caused by barrier impairment is SAM syndrome, which is caused by homozygous mutations in DSG1 (27). Loss of membranal DSG1 expression impairs cell-cell adhesion, leading to acantholysis in all patients. In addition, DSG1 deficiency stimulates production of Th2 cytokines, including TSLP, IL-5, TNF, and IL-13-induced periostin. These patients often have increased IgE levels, multiple food allergies, and EoE (27). As stated earlier, loss of DSG1 expression occurs in non-Mendelian EoE, supporting the generalizability of this mechanism. Heterozygous missense mutations in another desmosomal protein, desmoplakin $(D S P)$, also cause SAM syndrome with increased IgE levels, food allergies, hypereosinophilia, and EoE (79).

Other monogenic disorders highlight the balance between Th2 cells and Tregs as a causative mechanism in the etiology of GI allergic diseases. Deficiency of dedicator of cytokinesis 8 (DOCK8) results in an autosomal recessive, combined immunodeficiency and hyper-IgE syndrome characterized by sinopulmonary infections, eczema, viral skin infections, high specific serum IgE against food allergens, increased Th2 cells, and severe atopy, including food anaphylaxis (80). CD4 ${ }^{+} \mathrm{T}$ cells from DOCK8deficient patients are preferentially polarized to a Th2 effector phenotype, with defective ability to polarize toward a Th17 cytokine-producing state. In the absence of DOCK8, impaired 
Table 2. Common genetic variants that contribute to allergic GI diseases

$\begin{array}{lll}\text { Susceptibility locus } & & \text { Top candidate genes involved } \\ \begin{array}{ll}\text { Loci potentially involved in } \\ \text { barrier function }\end{array} & 18 q 21.3 & \text { FLG } \\ & 2 \mathrm{q} 23.3 & \begin{array}{l}\text { SERPINB7, SERPINB10 } \\ \text { CAPN14 }\end{array} \\ \begin{array}{l}\text { Loci potentially involved in } \\ \text { Th2 responses }\end{array} & 5 q 31.1-q 33 & \text { IL4, IL13, KIF3A } \\ & 5 q 22 & \text { TSLP, WDR36 } \\ \text { Loci potentially involved in } & 11 q 13 & \text { EMSY, LRRC32 } \\ \text { immune tolerance } & 6 p 21 & \text { HLADO, HLADR } \\ & 16 p 13 & \text { CLEC16A, DEXI, CITTA }\end{array}$

Susceptibility loci associated with allergic GI disorders.

\section{Atopic and immune disorders}

Food allergy, atopic dermatitis, allergic rhinitis, asthma, EoE

Food allergy

EoE

Food allergy, EoE, Crohn's disease, psoriasis, eczema

EoE, allergic sensitization, asthma, allergic rhinitis, atopic dermatitis

Food allergy, EoE, atopic dermatitis, asthma, allergic rhinitis, allergic sensitization, inflammatory bowel disease

Peanut allergy

EoE, IgA deficiency, and autoimmune diseases
STAT3 activation leads to production of Th2-biased cells at the expense of Th17 cells $(81,82)$. Interestingly, STAT3 mutations also result in hyper-IgE syndrome and $\mathrm{EoE}(83,84)$.

Loeys-Dietz syndrome (LDS) is an autosomal dominant connective tissue disorder caused by mutations in the genes encoding the TGF- $\beta$ receptor subunits TGFBR1 and TGFRBR2, which result in dysregulated TGF- $\beta$ signaling. The clinical phenotype includes predisposition to atopy including asthma, food anaphylaxis, eczema, AD, allergic rhinitis, and eosinophilic GI disorders (EGIDs). Patients with LDS have increased frequency of $\mathrm{CD}^{+} \mathrm{T}$ cells that express both FOXP3 and IL-13, and cultures of TGF- $\beta$-stimulated $\mathrm{CD} 4^{+} \mathrm{T}$ cells from patients with LDS produce increased Th2 cytokines compared with controls. These findings suggest that LDS mutations support Th2 skewing in a cell-autonomous manner (85) and highlight the key role of TGF- $\beta$, and likely Treg dysregulation, as a pathoetiologic mechanism in GI allergy including EGID.

In support of the key role of TGF- $\beta R 1$, individuals with a lossof-function mutation in ERBB2IP have increased risk for food allergic diseases including food anaphylaxis and EoE. Notably, ERBB2IP encodes ERBB2-interacting protein (ERBIN), a known anchor protein for the TGF- $\beta$ R1 downstream signaling molecules SMAD2 and SMAD3. Both STAT3 and ERBIN form a complex with SMAD2/3, inhibit SMAD2/3 activation, and suppress TGF- $\beta$ signaling. ERBIN loss of function impairs TGF- $\beta$ signaling and increases Treg numbers. Interestingly, DSG1 and ERBIN cooperate to repress MAPK signaling and promote keratinocyte differentiation, converging multiple relevant pathways in the development of food allergic responses $(84,86)$. Homozygous loss-of-function mutations in the gene CARMIL2 result in primary immunodeficiency disorder with variable phenotypic presentations including pulmonary allergy, various bacterial and fungal infections, dermatitis, and EoE. CARMIL2 contributes to the NF- $\mathrm{BB}$ pathway by stabilizing activated PKC $\theta$ microclusters at the immunological synapse, and loss-of-function mutations in this gene cause impaired Treg differentiation and function and cytoskeletal organization $(87,88)$. Summaries of genetic loci and of monogenic disorders associated with food allergic diseases are presented in Tables 2 and 3 , respectively.

\section{Environmental factors that contribute to food allergic diseases}

The pathoetiology of food allergic disease is likely due to a complex interplay of prenatal and postnatal environmental factors. Changes in food production, processing, and packaging (e.g., the use of pesticides, antibiotics, hormones, preservatives, heat denaturation, detergents, and chemicals) have been suggested to be linked to allergic diseases directly or indirectly (89-94).

The association of chemicals like bisphenol A (BPA) and phthalates with food allergy has been controversial (90). BPA is an endocrine disruptor with estrogenic activity that is commonly used as a component in polycarbonate plastic and epoxy resins. The main exposure to BPA is through food and beverages. Two studies demonstrated that BPA exposure altered the development of oral tolerance and decreased Treg number in mice $(95,96)$. Pre-

Table 3. Monogenic disorders associated with allergic GI disorders

\begin{tabular}{|c|c|c|c|}
\hline & Gene name & Disease & Atopic manifestation \\
\hline Barrier & $\begin{array}{l}\text { SPINK5, CDSN } \\
\text { DSG1, DSP }\end{array}$ & $\begin{array}{l}\text { Netherton syndrome } \\
\text { SAM syndrome }\end{array}$ & $\begin{array}{l}\text { Increased lgE levels, food allergy, atopic dermatitis, EoE } \\
\text { Increased lgE levels, multiple food allergies, EoE }\end{array}$ \\
\hline T helper responses & DOCK8 & Hyper-lgE syndrome & Eczema, increased lgE, food allergy \\
\hline T regulatory responses & $\begin{array}{l}\text { TCFBR1, TGFBR2 } \\
\text { ERBB2IP } \\
\text { STAT3 } \\
\text { CARMIL2 }\end{array}$ & $\begin{array}{l}\text { Loeys-Dietz syndrome } \\
\text { Hyper-IgE syndrome } \\
\text { Immunodeficiency disorders }\end{array}$ & $\begin{array}{l}\text { Asthma, food allergy, eczema, atopic dermatitis, allergic rhinitis, EGIDs } \\
\text { Food allergy, EoE } \\
\text { Increased IgE, food allergy, atopic dermatitis, eczema } \\
\text { EoE, dermatitis, recurrent skin and chest infections }\end{array}$ \\
\hline
\end{tabular}


A
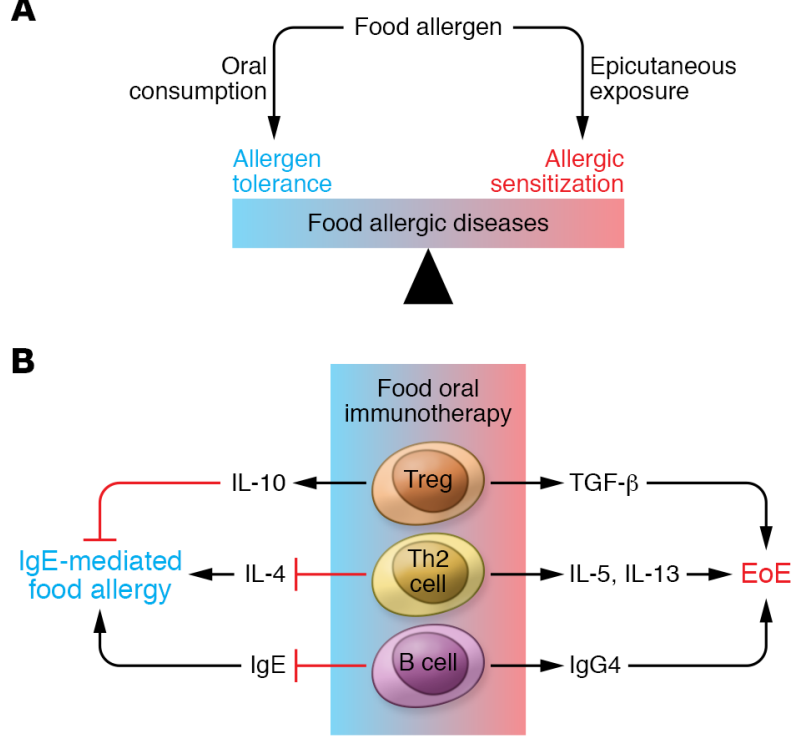

Figure 2. The effects of different allergen exposure paths on $\mathrm{GI}$ allergic diseases. (A) The dual allergen exposure hypothesis suggests that (a) environmental exposure to antigens in early life, specifically via the skin, increases the risk of developing food allergic disease later in life by inducing allergic sensitization, and (b) oral consumption of high amounts of antigen in early life decreases the risk of developing food allergic disease later in life by inducing immune tolerance. (B) OIT induces Treg expansion and release of IL-10. IL-10 promotes Treg cell differentiation and inhibits Th2 cell differentiation. As a result, less IL-4 is produced, which decreases IgE isotype switch recombination in local B cells and Th2 cell differentiation. OIT-induced TGF- $\beta$ production by Tregs is also considered pathogenic in EoE and promotes tissue fibrosis, epithelial-to-mesenchymal transition, and smooth muscle contraction. OIT, at least in the setting of EoE, does not effectively dampen Th2 cell production of IL-5 and IL-13, which promote EoE. Increased IgC4 production by B cells is thought to be protective against IgE-mediated allergic GI diseases but might be pathogenic in EoE.

natal exposure of rats to BPA resulted in decreased Tregs and DCs in the spleen and mesenteric lymph nodes (97). In addition, glycated proteins, found in many foods particularly after super-high heating, such as microwave cooking, frying, and barbecuing, have been suggested to serve as alarmins that promote type 2 responses (94). Finally, exposure to certain drugs during infancy, particularly histamine 2 receptor antagonists and proton pump inhibitors, also increases risk for food anaphylaxis and $\operatorname{EoE}(71,98,99)$.

Past assumptions were that early exposure to food was a risk factor for the development of food allergy. However, current evidence supports that early exposure to food antigens is likely protective, at least for the development of food anaphylaxis $(100,101)$. The dual allergen exposure hypothesis suggests that epicutaneous exposure to antigens induces allergic sensitization, particularly in individuals with impaired skin barrier, whereas oral consumption of high amounts of antigen induces tolerance (Figure 2A). Several studies on peanut allergy showed striking results. Du Toit et al. (102) reported that the prevalence of peanut allergy in infants in the United Kingdom is 10 -fold higher than the prevalence of peanut allergy in infants in Israel. This study revealed a link between early consumption of food antigens and tolerance induction, suggesting that the dramatic increase in infant peanut consumption in Israel is the main reason for the low prevalence of peanut allergy (102,
103). The dual allergen exposure hypothesis has been solidified by the Learning Early About Peanut Allergy (LEAP) study, a controlled clinical study that aimed to determine the best strategy to prevent peanut allergy in children. The study found that infants that had a negative skin-prick test to peanut were at higher risk for developing peanut allergy at 60 months of age if they avoided peanut consumption than if they were peanut consumers. In the group of infants that had a positive skin-prick test to peanut, the peanut-avoiding children were 3 times more likely to have peanut allergy at the age of 60 months than were peanut consumers (104). This study showed that peanut consumption can be protective even in high-risk infants who were environmentally exposed and sensitized to peanut. This protective effect remained even if the children who consumed peanut avoided peanut for the following 12 months (105). These findings have now been put into clinical practice by recommendation of peanut consumption in the first year of life (106).

Variance in the rates of allergic GI disease are found by geography and ethnicity. For example, non-US-born children who migrate to the US have decreased risk of food allergy independent of ethnicity (107). Similarly, Asian children who migrate to Australia have decreased risk to develop nut allergy (108). In contrast, among US-born children, the children of immigrants were at the highest risk for food anaphylaxis (107). Ethnic minorities in developed countries tend to have a higher rate of allergic sensitization. Higher levels of food-specific IgE have been observed in black children than in white children (109). These differences are probably attributable to differences in genetics and lifestyle.

Vitamin D deficiency has been associated with increased risk of peanut sensitization, peanut allergy, and IgE-mediated egg allergy $(110,111)$. The mechanism is thought to be mediated by vitamin D-driven suppression of IgE production and the promotion of tolerogenic DC and Treg maturation, which induces immune tolerance. In contrast, several studies have shown that excess vitamin D consumption increases the risk for allergies (112). Further studies are needed to establish the driving mechanisms, the dose response, and timing relationships.

Microbial dysbiosis. Decreased exposure to pathogens, such as Helicobacter pylori, has been reported to contribute to the development of allergies (113). Preterm delivery, cesarean section, and antibiotic use in infancy, which affect/alter the microbiome, are more common in EoE than control groups $(71,99)$. A large study in Japan revealed that food allergy risk is decreased with increasing birth order, possibly reflecting exposure to more infections from siblings $(114,115)$. Having a dog is a protective factor against IgE-mediated food allergy and EoE $(71,115)$. Living on a farm is associated with decreased rates of food allergy sensitization in children (116). These data substantiate a key role for exposure, particularly related to dysbiosis, in the etiology of GI allergic diseases.

It is notable that germ-free mice are more susceptible to Th2 responses (117-119). Azad et al. demonstrated that microbiome dysbiosis in early infancy is associated with food sensitization later in life (120). In another study, the intestinal microbiota of infants with milk allergy was significantly different from that of control infants (121). Animal studies suggest that gut colonization of commensal microbes in early life influences tolerance versus allergic sensitization to environmental exposures encountered later in life via several 
mechanisms. In the GI tract, dietary fiber is converted to short-chain fatty acids (mainly acetate, butyrate, and propionate) through the actions of commensal anaerobic bacteria. The receptors for these metabolites (GPCRs such as GPR43/ FFAR2, GPR41/FFAR3, and GPR109A/HCAR2) are expressed by Tregs, Th2 cells, neutrophils, macrophages, DCs, mast cells, epithelial cells, and adipocytes in the intestine and particularly the colon $(11,122)$. Butyrate and propionate regulate differentiation of colonic Tregs that suppress inflammatory and allergic responses $(123,124)$. Acetate regulates gut epithelial integrity (125). Short-chain fatty acids influence the severity of allergic inflammation in the lungs by regulating DCs and Th2 cells (126). Alterations in the intestinal microbiome homeostasis regulate the epithelial inflammasome pathway and IL-18 production, which can be protective processes against intestinal damage and colitis (127). Dietary fiber and microbiota also promote chromatin changes by regulating histone acetylation and methylation in multiple host tissues (122). Barletta et al. showed that probiotic supplementation in a murine model ameliorates peanut allergy by increasing TGF- $\beta$ levels (128). Atarashi et al. successfully isolated Treg-inducing bacterial strains from the healthy human indigenous microbiota. Inoculation of these bacteria into germ-free mice revealed multiple strains of clusters IV, XIVa, and XVIII of Clostridia that induced Treg expansion and antiinflammatory cytokine production (129). Colonization of germ-free mice with feces from healthy or cow's milk-allergic (CMA) infants revealed that the CMA-colonized mice had increased anaphylactic responses compared with healthy-colonized mice and exhibited differential gene signature in the ileal epithelium. In the same paper, the authors also identified the clostridial species Anaerostipes caccae as a protecting species against an allergic response to food (130). Though the effect of probiotic supplements on $\mathrm{AD}$ and eczema in clinical trials seems promising (131), their effect on GI allergy remains controversial $(132,133)$. Zmora et al. investigated the murine and human mucosa-associated microbiome along the GI tract with and without supplementing with multiple strains of bacteria (mainly from the genera Lactobacillus and Bifidobacterium) and reported that humans can be clustered into two groups: permissive or resistant to mucosal probiotic colonization (134). In addition, the use of empiric probiotics after the use of antibiotics could delay the gut microbiome and transcriptome reconstitution, whereas fecal microbiome transplantation induced rapid microbiome reconstitution (135). These studies raise the hypothesis that probiotic treatment may be more beneficial as a patient-tailored therapy than as an empiric one-forall approach. Further studies are required to identify specific strains and, particularly, certain species of the genus Clostridium, which will be adjusted to the host microbiome in a personalized manner. Perhaps healthy dietary guidelines can protect from GI allergic diseases by promoting a balanced GI microbiome.

\section{Oral immunotherapy and the mechanism of desensitization}

Food allergen immunotherapy is a process by which an atopic individual is exposed to initially small but gradually increasing quantities of allergens in order to achieve tolerance or sustained unresponsiveness of the immune system, thereby decreasing the probability of an allergic reaction toward the allergen (136). The exposure to antigens can be epicutaneous, sublingual, or oral. The mechanisms by which immunotherapy is mediated are under extensive investigation. The reduction in sensitivity after immunotherapy is associated with a decreased ratio of $\operatorname{IgE} / \operatorname{IgG} 2 \mathrm{a}$ and increased antigen-specific IgG4 and IgA antibodies (137), decreased mast cell and basophil reactivity, and increased Tregs (138).

The extent of protection following immunotherapy is highly variable. Epicutaneous immunotherapy in a murine peanut allergy model revealed hypermethylation of the Gata3 promoter and hypomethylation of the Foxp3 promoter in Tregs, leading to a decrease in Th 2 cells and an increase in Tregs, respectively. This was associated with sustained protection from food anaphylaxis (139).

Multiple case reports and meta-analysis of oral immunotherapy (OIT) reveal that immunotherapy for IgE-mediated food allergy may cause development of EGIDs (140-144). In murine models of EoE, epicutaneous allergen exposure primes for EoE (145), whereas epicutaneous immunotherapy induces a persistent resolution of esophageal eosinophilia (138), suggesting the skin's potential to positively or negatively modify EoE-related responses. During OIT, Treg-mediated Th2 immunity in mice is modified, likely concentrated on inhibiting IL-4- and IgEmediated responses but not sufficiently inhibiting IL-5- and IL-13-mediated responses. During experimental OIT, the induced Treg response is sufficient to repress IL-4/IgE but not experimental EoE development. It is unknown whether OIT-associated EoE is due to the unmasking of preexisting, lower-grade esophageal eosinophilia or the initiation of new esophageal disease. Interesting observations have shown that IgG4 levels are increased in EoE (146-149). IgG4 is thought to be a neutralizing antibody because it binds weakly to activating Fc $\gamma$ receptors. Treg-derived IL-10 and TGF- $\beta$ likely regulate IgG4 production, connecting these pathways. During early life, foodspecific IgG4 increases with continual peanut exposure; notably, a similar IgG4 increase occurs during OIT. Why the EoE response occurs only in a subset of OIT-treated patients may be genetically dictated. Figure 2B summarizes what OIT teaches us about the mechanism of EoE and IgE-mediated food allergy.

\section{Prevention and therapies}

The most common approach to treat GI allergies is food allergen avoidance. Dietary treatment requires strict guidelines and educational interventions, especially in EoE, in which multiple foods drive disease and patients often have to remove the top six food allergen groups (milk, wheat, soy, egg, nuts/tree nuts, and fish/shellfish). Self-injectable epinephrine can prevent fatal consequences in life-threatening IgE-mediated food allergy. Because a dry, impaired skin barrier may increase the risk for GI allergic diseases, a few studies have examined whether treating eczema may decrease the risk of food anaphylaxis (150). Consistent, routine application of emollients has been shown to prevent $\operatorname{AD}(151,152)$. Lowe et al. showed that prevention of eczema using lipid replacement therapy reduced food sensitization in a pilot trial (153). Likewise, in support of the dual allergen hypothesis, oral consumption of food allergens early in life prevents IgE 


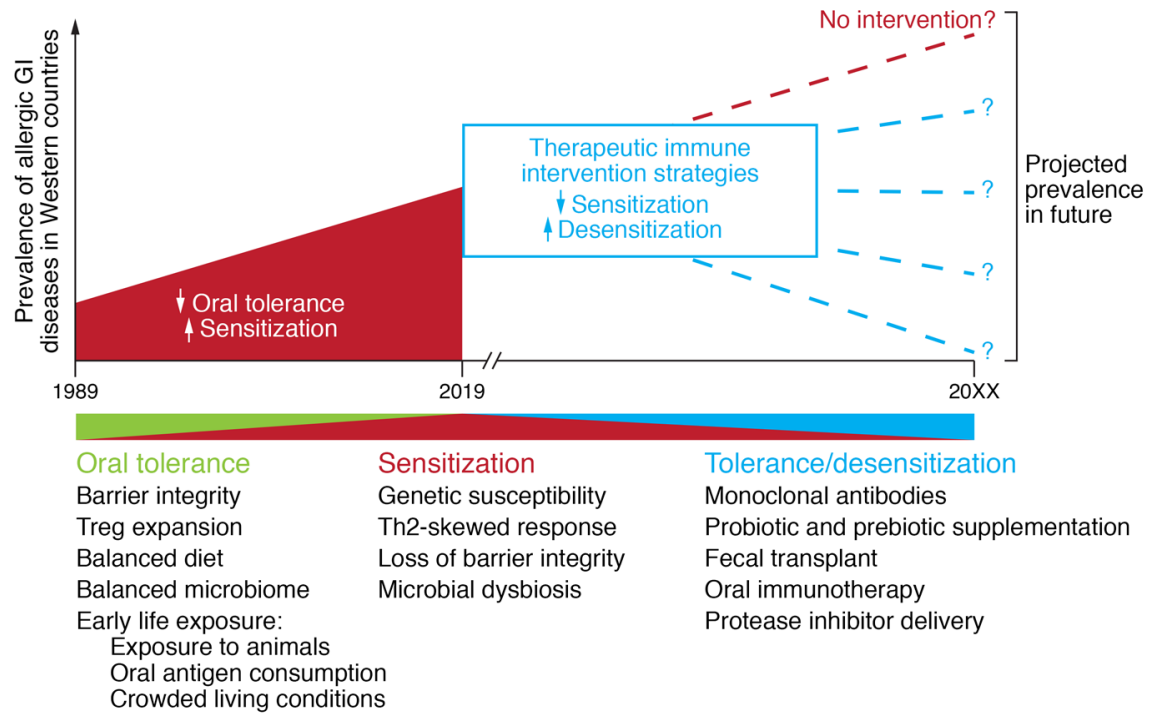

Figure 3. Factors that contribute to immunologic tolerance, sensitization, and desensitization. Immune tolerance toward an antigen breaks down when a danger signal is produced instead of a tolerance signal. Long-lasting adaptive immune responses are influenced by a sequence of environmental and genetic factors. The increase in the prevalence rate of allergic GI diseases over the past several decades is mainly attributed to changes in environmental factors. Future studies that will decipher the pathways toward sensitization and desensitization will provide the bases for therapeutic immune intervention. sensitization and food anaphylaxis, at least in the case of peanut allergy $(100,104,105,115)$.

Other treatment options that currently exist include corticosteroids, mast cell inhibitors, $\mathrm{H} 2$ antagonists, and leukotriene receptor antagonists. For diseases such as EoE, topical esophageal delivery of swallowed corticosteroids can be effective (154). However, EoE reoccurs nearly universally after cessation of therapy.

Non-IgE-mediated food allergies are typically resolved between 1 and 3 years of age, and the serotonin 5-HT3 receptor antagonist ondansetron has proven beneficial in some cases (155).

Anti-human IgE antibody (anti-IgE; omalizumab) was the first biologic agent approved for treating asthma. Omalizumab treatment with allergen immunotherapy helps to potentiate increases in Treg activity by reversing the Th2 cell-like program (156). Using allergen OIT with anti-IgE antibodies in clinical studies showed promise, although not in all studies (157-160). Anti-IL-5 antibodies (mepolizum$\mathrm{ab}$, reslizumab) have been FDA-approved for treating eosinophilic asthma (161), and several clinical trials support their effectiveness for EoE, although while esophageal eosinophilia improved, clinical symptoms were only modestly improved compared with typical improvements seen with topical glucocorticoids or dietary elimination therapy (162-164). Treatment of EoE with anti-IL-13 antibodies (QAX576 and RPC4046) produced favorable early results (165-167). Early phase II trials of anti-IL-4R $\alpha$ (dupilumab) also yielded positive results (168), substantiating preclinical models based on IL-13-driven EoE-like responses (169, 170). Ongoing clinical studies are evaluating the effectiveness of targeting the IL-5 receptor IL-5R $\alpha$, anti-Siglec-8 (an eosinophil and mast cell inhibitory receptor), and anti-IL-4R $\alpha$ for a number of GI allergic diseases, including EGIDs and food anaphylaxis. The effect of anti-TSLP treatment (AMG157) on EoE or IgE-mediated food allergy is unknown. However, in a study of asthma, AMG157 treatment showed positive results, especially for asthma that remained uncontrolled despite treatment (171). IL-33 was shown necessary for sensitization to peanut allergens and allergic responses in mouse models of food anaphylaxis (172). Encouraging preliminary findings from a clinical trial of anti-IL-33 in peanut allergy have been recently presented (available at https://www. anaptysbio.com/pipeline/etokimab/) (173).

\section{Future directions}

It is now understood that oral tolerance under healthy conditions is characterized by barrier integrity and Treg expansion promoted by early-life exposures through diet and microbiome composition. In contrast, loss of tolerance is characterized by loss of barrier integrity, microbial dysbiosis, and exaggerated type 2 immunity influenced by genetic susceptibility elements (including common variants as well as rare mutations associated with Mendelian diseases). Treatment is focused on promoting antigen desensitization and restoring long-term oral tolerance, currently centered around oral immunotherapy approaches, but future strategies include administering concurrent biologic therapies (e.g., monoclonal antibodies), manipulating commensal organisms through probiotics, prebiotics, and fecal transplantation, and reestablishing the protease/antiprotease balance (Figure 3). Currently, there is an unmet need to find more diagnostic markers and inhibitory strategies for GI allergic diseases. Better identification of individuals with increased risk of disease susceptibility will help future prevention of disease onset. Additional translational research will likely help in developing new treatment strategies and tailored medicine.

\section{Acknowledgments}

This work was supported in part by NIH grants R01 AI124355, R37 A1045898, and U19 AI070235; the Campaign Urging Research for Eosinophilic Disease (CURED) Foundation; the Sunshine Charitable Foundation and its supporters, Denise A. Bunning and David G. Bunning; and the Consortium of Eosinophilic Gastrointestinal Disease Researchers (CEGIR; U54 AI117804) as part of the Rare Diseases Clinical Research Network, an initiative of the Office of Rare Diseases Research, National Center for Advancing Translational Sciences (NCATS), which is cofunded by the National Institute of Allergy and Infectious Diseases, the National Institute 
of Diabetes and Digestive and Kidney Diseases, and the NCATS. CEGIR is also supported by patient advocacy groups including the American Partnership for Eosinophilic Disorders, the Campaign Urging Research for Eosinophilic Disease (CURED), and the Eosinophilic Family Coalition.
Address correspondence to: Marc E. Rothenberg, Cincinnati Children's Hospital Medical Center, Allergy and Immunology, MLC 7028, 3333 Burnet Avenue, Allergy \& Clinical Immunology, Cincinnati, Ohio 45229-3039, USA. Phone: 513.636.7210; Email: Rothenberg@cchmc.org.
1. Renz H, et al. Food allergy. Nat Rev Dis Primers. 2018;4:17098.

2. Yu W, Freeland DMH, Nadeau KC. Food allergy: immune mechanisms, diagnosis and immunotherapy. Nat Rev Immunol. 2016;16(12):751-765.

3. Hammad H, Lambrecht BN. Barrier epithelial cells and the control of type 2 immunity. Immunity. 2015;43(1):29-40.

4. McDole JR, et al. Goblet cells deliver luminal antigen to CD103+ dendritic cells in the small intestine. Nature. 2012;483(7389):345-349.

5 . Worbs $\mathrm{T}$, et al. Oral tolerance originates in the intestinal immune system and relies on antigen carriage by dendritic cells. J Exp Med. 2006;203(3):519-527.

6. Shan M, et al. Mucus enhances gut homeostasis and oral tolerance by delivering immunoregulatory signals. Science. 2013;342(6157):447-453.

7. Schulke S. Induction of interleukin-10 producing dendritic cells as a tool to suppress allergenspecific T helper 2 responses. Front Immunol. 2018;9:455.

8. Wing K, Sakaguchi S. Regulatory T cells exert checks and balances on self tolerance and autoimmunity. Nat Immunol. 2010;11(1):7-13.

9. Beppu LY, Anilkumar AA, Newbury RO, Dohil R, Broide DH, Aceves SS. TGF- $\beta 1$-induced phospholamban expression alters esophageal smooth muscle cell contraction in patients with eosinophilic esophagitis. J Allergy Clin Immunol. 2014;134(5):1100-1107.e4.

10. Stuck MC, Straumann A, Simon HU. Relative lack of $\mathrm{T}$ regulatory cells in adult eosinophilic esophagitis - no normalization after corticosteroid therapy. Allergy. 2011;66(5):705-707.

11. Wen T, et al. Single-cell RNA sequencing identifies inflammatory tissue $\mathrm{T}$ cells in eosinophilic esophagitis. J Clin Invest. In press.

12. Rekima A, et al. Long-term reduction in food allergy susceptibility in mice by combining breastfeeding-induced tolerance and TGF- $\beta$ enriched formula after weaning. Clin Exp Allergy. 2017;47(4):565-576.

13. Ohsaki A, et al. Maternal IgG immune complexes induce food allergen-specific tolerance in offspring. JExp Med. 2018;215(1):91-113.

14. Alduraywish SA, et al. The march from early life food sensitization to allergic disease: a systematic review and meta-analyses of birth cohort studies. Allergy. 2016;71(1):77-89.

15. Shaker M, Murray RGP, Mann JA. The ins and outs of an 'outside-in' view of allergies: atopic dermatitis and allergy prevention. Curr Opin Pediatr. 2018;30(4):576-581.

16. Hill DA, Grundmeier RW, Ramos M, Spergel JM. Eosinophilic esophagitis is a late manifestation of the allergic march. J Allergy Clin Immunol Pract. 2018;6(5):1528-1533.

17. Bartnikas LM, et al. Epicutaneous sensitization results in IgE-dependent intestinal mast cell expansion and food-induced anaphylaxis. JAllergy Clin Immunol. 2013;131(2):451-460.e1.

18. Strid J, Hourihane J, Kimber I, Callard R, Strobel S. Epicutaneous exposure to peanut protein prevents oral tolerance and enhances allergic sensitization. Clin Exp Allergy. 2005;35(6):757-766.

19. Noti M, et al. Exposure to food allergens through inflamed skin promotes intestinal food allergy through the thymic stromal lymphopoietinbasophil axis. J Allergy Clin Immunol. 2014;133(5):1390-1399.e1.

20. Kelleher MM, et al. Skin barrier impairment at birth predicts food allergy at 2 years of age. J Allergy Clin Immunol. 2016;137(4):1111-1116.e8.

21. Marenholz I, et al. Genome-wide association study identifies the SERPINB gene cluster as a susceptibility locus for food allergy. Nat Commun. 2017;8(1):1056.

22. Kottyan LC, et al. Genome-wide association analysis of eosinophilic esophagitis provides insight into the tissue specificity of this allergic disease. Nat Genet. 2014;46(8):895-900.

23. McAleer MA, Irvine AD. The multifunctional role of filaggrin in allergic skin disease. JAllergy Clin Immunol. 2013;131(2):280-291.

24. Sherrill JD, et al. Desmoglein-1 regulates esophageal epithelial barrier function and immune responses in eosinophilic esophagitis. Mucosal Immunol. 2014;7(3):718-729.

25. Katzka DA, et al. Endoscopic mucosal impedance measurements correlate with eosinophilia and dilation of intercellular spaces in patients with eosinophilic esophagitis. Clin Gastroenterol Hepatol. 2015;13(7):1242-1248.e1.

26. Capocelli KE, Fernando SD, Menard-Katcher C, Furuta GT, Masterson JC, Wartchow EP. Ultrastructural features of eosinophilic oesophagitis: impact of treatment on desmosomes. J Clin Pathol. 2015;68(1):51-56.

27. Samuelov L, et al. Desmoglein 1 deficiency results in severe dermatitis, multiple allergies and metabolic wasting. Nat Genet. 2013;45(10):1244-1248.

28. Davis BP, et al. Eosinophilic esophagitis-linked calpain 14 is an IL-13-induced protease that mediates esophageal epithelial barrier impairment. JCI Insight. 2016;1(4):e86355.

29. Azouz NP, et al. The antiprotease SPINK7 serves as an inhibitory checkpoint for esophageal epithelial inflammatory responses. Sci Transl Med. 2018;10(444):eaap9736.

30. Blanchard C, et al. Coordinate interaction between IL-13 and epithelial differentiation cluster genes in eosinophilic esophagitis. J Immunol. 2010;184(7):4033-4041.

31. Athari SS, Athari SM, Beyzay F, Movassaghi M, Mortaz E, Taghavi M. Critical role of Toll-like receptors in pathophysiology of allergic asthma. Eur J Pharmacol. 2017;808:21-27.

32. Ramachandran R, Noorbakhsh F, Defea K,
Hollenberg MD. Targeting proteinase-activated receptors: therapeutic potential and challenges. Nat Rev Drug Discov. 2012;11(1):69-86.

33. Frateschi S, et al. PAR2 absence completely rescues inflammation and ichthyosis caused by altered CAP1/Prss8 expression in mouse skin. Nat Commun. 2011;2:161.

34. Takai T, et al. TSLP expression induced via Tolllike receptor pathways in human keratinocytes. Meth Enzymol. 2014;535:371-387.

35. Turner MJ, Zhou B. A new itch to scratch for TSLP. Trends Immunol. 2014;35(2):49-50.

36. Sicherer SH, Furlong TJ, Maes HH, Desnick RJ, Sampson HA, Gelb BD. Genetics of peanut allergy: a twin study. JAllergy Clin Immunol. 2000;106(1 pt 1):53-56.

37. Tsai HJ, et al. Familial aggregation of food allergy and sensitization to food allergens: a family-based study. Clin Exp Allergy. 2009;39(1):101-109.

38. Alexander ES, et al. Twin and family studies reveal strong environmental and weaker genetic cues explaining heritability of eosinophilic esophagitis. J Allergy Clin Immunol. 2014;134(5):1084-1092.e1.

39. Liu X, et al. Genetic and environmental contributions to allergen sensitization in a Chinese twin study. Clin Exp Allergy. 2009;39(7):991-998.

40. Brown SJ, et al. Loss-of-function variants in the filaggrin gene are a significant risk factor for peanut allergy. J Allergy Clin Immunol. 2011;127(3):661-667.

41. Wu L, et al. Filaggrin and tight junction proteins are crucial for IL-13-mediated esophageal barrier dysfunction. Am J Physiol Gastrointest Liver Physiol. 2018;315(3):G341-G350.

42. Rochman M, et al. Profound loss of esophageal tissue differentiation in patients with eosinophilic esophagitis. J Allergy Clin Immunol. 2017;140(3):738-749.e3.

43. Martin LJ, et al. Eosinophilic esophagitis (EoE) genetic susceptibility is mediated by synergistic interactions between EoE-specific and general atopic disease loci. JAllergy Clin Immunol. 2018;141(5):1690-1698.

44. Sleiman PMA, March M, Hakonarson H. The genetic basis of eosinophilic esophagitis. Best Pract Res Clin Gastroenterol. 2015;29(5):701-707.

45. Marsh DG, et al. Linkage analysis of IL4 and other chromosome 5q31.1 markers and total serum immunoglobulin E concentrations. Science. 1994;264(5162):1152-1156.

46. Namjou B, et al. Phenome-wide association study (PheWAS) in EMR-linked pediatric cohorts, genetically links PLCL1 to speech language development and IL5-IL13 to Eosinophilic Esophagitis. Front Genet. 2014;5:401.

47. Armuzzi A, et al. Genotype-phenotype analysis of the Crohn's disease susceptibility haplotype on chromosome 5q31. Gut. 2003;52(8):1133-1139.

48. Tsoi LC, et al. Enhanced meta-analysis and repli- 
cation studies identify five new psoriasis susceptibility loci. Nat Commun. 2015;6:7001.

49. Forrest $S$, et al. Identifying genes predisposing to atopic eczema. J Allergy Clin Immunol. 1999;104(5):1066-1070.

50. Chu Y, Hua L, Liu Q, Bao Y. A common variant associated with asthma, interleukin $13 \mathrm{R} 130 \mathrm{Q}$, promotes the production of IgE. Int J Immunogenet. 2012;39(4):308-313.

51. Cui L, et al. IL-13 polymorphisms contribute to the risk of asthma: a meta-analysis. Clin Biochem. 2012;45(4-5):285-288.

52. Hershey GK, Friedrich MF, Esswein LA, Thomas ML, Chatila TA. The association of atopy with a gain-of-function mutation in the alpha subunit of the interleukin-4 receptor. NEngl J Med. 1997;337(24):1720-1725.

53. Ziegler SF, Artis D. Sensing the outside world: TSLP regulates barrier immunity. Nat Immunol. 2010;11(4):289-293.

54. Rothenberg ME, et al. Common variants at $5 \mathrm{q} 22$ associate with pediatric eosinophilic esophagitis. Nat Genet. 2010;42(4):289-291.

55. Sleiman PM, et al. GWAS identifies four novel eosinophilic esophagitis loci. Nat Commun. 2014;5:5593.

56. Asai Y, et al. Genome-wide association study and meta-analysis in multiple populations identifies new loci for peanut allergy and establishes C11orf30/EMSY as a genetic risk factor for food allergy. J Allergy Clin Immunol. 2018;141(3):991-1001.

57. Kottyan LC, Rothenberg ME. Genetics of eosinophilic esophagitis. Mucosal Immunol. 2017;10(3):580-588

58. Cianferoni A, Spergel JM. From genetics to treatment of eosinophilic esophagitis. Curr Opin Allergy Clin Immunol. 2015;15(5):417-425.

59. Kottyan LC, et al. Genetic variants at the $16 \mathrm{p} 13$ locus confer risk for eosinophilic esophagitis [published online ahead of print June 8, 2018]. Genes Immun. https://doi.org/10.1038/s41435018-0034-z

60. Esparza-Gordillo J, et al. A common variant on chromosome $11 \mathrm{q} 13$ is associated with atopic dermatitis. Nat Genet. 2009;41(5):596-601.

61. Ferreira MA, et al. Identification of IL6R and chromosome 11q13.5 as risk loci for asthma. Lancet. 2011;378(9795):1006-1014.

62. Bonnelykke K, et al. Meta-analysis of genomewide association studies identifies ten loci influencing allergic sensitization. Nat Genet. 2013;45(8):902-906.

63. Ramasamy A, et al. A genome-wide meta-analysis of genetic variants associated with allergic rhinitis and grass sensitization and their interaction with birth order. J Allergy Clin Immunol. 2011;128(5):996-1005.

64. Tran DQ, Andersson J, Wang R, Ramsey H, Unutmaz D, Shevach EM. GARP (LRRC32) is essential for the surface expression of latent TGF-beta on platelets and activated FOXP3 ${ }^{+}$ regulatory T cells. Proc Natl Acad Sci U S A. 2009;106(32):13445-13450.

65. Hong X, et al. Genome-wide association study identifies peanut allergy-specific loci and evidence of epigenetic mediation in US children. Nat Commun. 2015;6:6304.
66. LeibundGut-Landmann S, et al. Mini-review: specificity and expression of CIITA, the master regulator of MHC class II genes. Eur J Immunol. 2004;34(6):1513-1525.

67. Devaiah BN, Singer DS. CIITA and its dual roles in MHC gene transcription. Front Immunol. 2013;4:476.

68. Ferreira RC, et al. Association of IFIH1 and other autoimmunity risk alleles with selective IgA deficiency. Nat Genet. 2010;42(9):777-780.

69. Singh K, Chang C, Gershwin ME. IgA deficiency and autoimmunity. Autoimmun Rev. 2014;13(2):163-177.

70. Leikfoss IS, et al. Multiple sclerosis-associated single-nucleotide polymorphisms in CLEC16A correlate with reduced SOCS1 and DEXI expression in the thymus. Genes Immun . 2013;14(1):62-66.

71. Jensen ET, Kuhl JT, Martin LJ, Langefeld CD, Dellon ES, Rothenberg ME. Early-life environmental exposures interact with genetic susceptibility variants in pediatric patients with eosinophilic esophagitis. J Allergy Clin Immunol. 2018;141(2):632-637.e5.

72. Brough HA, et al. Peanut allergy: effect of environmental peanut exposure in children with filaggrin loss-of-function mutations. J Allergy Clin Immunol. 2014;134(4):867-875.e1.

73. Furio L, Hovnanian A. Netherton syndrome: defective kallikrein inhibition in the skin leads to skin inflammation and allergy. Biol Chem. 2014;395(9):945-958.

74. Kusunoki T, et al. SPINK5 polymorphism is associated with disease severity and food allergy in children with atopic dermatitis. JAllergy Clin Immunol. 2005;115(3):636-638.

75. Simon D, Radonjic-Hosli S, Straumann A, Yousefi $\mathrm{S}$, Simon HU. Active eosinophilic esophagitis is characterized by epithelial barrier defects and eosinophil extracellular trap formation. Allergy. 2015;70(4):443-452.

76. Simon D, et al. Evidence of an abnormal epithelial barrier in active, untreated and corticosteroidtreated eosinophilic esophagitis. Allergy. 2018;73(1):239-247.

77. Paluel-Marmont C, et al. Eosinophilic esophagitis and colonic mucosal eosinophilia in Netherton syndrome. JAllergy Clin Immunol. 2017;139(6):2003-2005.e1.

78. Oji V, et al. Loss of corneodesmosin leads to severe skin barrier defect, pruritus, and atopy: unraveling the peeling skin disease. Am J Hum Genet. 2010;87(2):274-281.

79. McAleer MA, et al. Severe dermatitis, multiple allergies, and metabolic wasting syndrome caused by a novel mutation in the $\mathrm{N}$-termina plakin domain of desmoplakin. J Allergy Clin Immunol. 2015;136(5):1268-1276.

80. Aydin SE, et al. DOCK8 deficiency: clinical and immunological phenotype and treatment options - a review of 136 patients. J Clin Immunol. 2015;35(2):189-198.

81. Keles S, et al. Dedicator of cytokinesis 8 regulates signal transducer and activator of transcription 3 activation and promotes TH17 cell differentiation J Allergy Clin Immunol. 2016;138(5):1384-1394.e2

82. Tangye SG, et al. Dedicator of cytokinesis 8deficient $\mathrm{CD}^{+}{ }^{+} \mathrm{T}$ cells are biased to a TH2 effector fate at the expense of TH1 and TH17 cells.
JAllergy Clin Immunol. 2017;139(3):933-949.

83. Arora M, et al. Gastrointestinal manifestations of STAT3-deficient Hyper-IgE syndrome. J Clin Immunol. 2017;37(7):695-700.

84. Lyons JJ, et al. ERBIN deficiency links STAT3 and TGF- $\beta$ pathway defects with atopy in humans JExp Med. 2017;214(3):669-680.

85. Frischmeyer-Guerrerio PA, et al. TGF receptor mutations impose a strong predisposition for human allergic disease. Sci Transl Med. 2013;5(195):195ra94.

86. Harmon RM, et al. Desmoglein-1/Erbin interaction suppresses ERK activation to support epidermal differentiation. JClin Invest. 2013;123(4):1556-1570.

87. Schober T, et al. A human immunodeficiency syndrome caused by mutations in CARMIL2. Nat Commun. 2017;8:14209.

88. Alazami AM, et al. Novel CARMIL2 mutations in patients with variable clinical dermatitis, infections, and combined immunodeficiency. Front Immunol. 2018;9:203.

89. Patel O, Syamlal G, Henneberger PK, Alarcon WA, Mazurek JM. Pesticide use, allergic rhinitis, and asthma among US farm operators. J Agromedicine. 2018;23(4):327-335.

90. Nygaard UC, et al. Early life exposure to bisphenol A investigated in mouse models of airway allergy, food allergy and oral tolerance. Food Chem Toxicol. 2015;83:17-25.

91. McNeil BD, et al. Identification of a mast-cell-specific receptor crucial for pseudo-allergic drug reactions. Nature. 2015;519(7542):237-241.

92. Jimenez-Saiz R, Benede S, Molina E, LopezExposito I. Effect of processing technologies on the allergenicity of food products. Crit Rev Food Sci Nutr. 2015;55(13):1902-1917.

93. Zaknun D, Schroecksnadel S, Kurz K, Fuchs D. Potential role of antioxidant food supplements, preservatives and colorants in the pathogenesis of allergy and asthma. Int Arch Allergy Immunol. 2012;157(2):113-124.

94. Smith PK, Masilamani M, Li XM, Sampson HA. The false alarm hypothesis: food allergy is associated with high dietary advanced glycation end-products and proglycating dietary sugars that mimic alarmins. J Allergy Clin Immunol. 2017;139(2):429-437.

95. Ohshima Y, Yamada A, Tokuriki S, Yasutomi M, Omata N, Mayumi M. Transmaternal exposure to bisphenol A modulates the development of oral tolerance. Pediatr Res. 2007;62(1):60-64.

96. Herberth G, et al. Prenatal phthalate exposure associates with low regulatory $\mathrm{T}$-cell numbers and atopic dermatitis in early childhood: results from the LINA mother-child study. JAllergy Clin Immunol. 2017;139(4):1376-1379.e8.

97. Menard S, et al. Perinatal exposure to a low dose of bisphenol A impaired systemic cellular immune response and predisposes young rats to intestinal parasitic infection. PLoS One. 2014;9(11):e112752

98. Mitre E, Susi A, Kropp LE, Schwartz DJ, Gorman $\mathrm{GH}$, Nylund CM. Association between use of acid-suppressive medications and antibiotics during infancy and allergic diseases in early childhood. JAMA Pediatr. 2018;172(6):e180315. 
99. Jensen ET, Kappelman MD, Kim HP, RingelKulka T, Dellon ES. Early life exposures as risk factors for pediatric eosinophilic esophagitis. J Pediatr Gastroenterol Nutr. 2013;57(1):67-71.

100.du Toit G, Tsakok T, Lack S, Lack G. Prevention of food allergy. JAllergy Clin Immunol. 2016;137(4):998-1010.

101.Sicherer SH, Sampson HA. Food allergy: a review and update on epidemiology, pathogenesis, diagnosis, prevention, and management. JAllergy Clin Immunol. 2018;141(1):41-58.

102. Du Toit G, et al. Early consumption of peanuts in infancy is associated with a low prevalence of peanut allergy. JAllergy Clin Immunol. 2008;122(5):984-991.

103. Katz Y, Rothenberg ME. Infant feeding: swinging the pendulum from late to early introduction of food. Isr Med Assoc J. 2016;18(11):684-688.

104.Du Toit G, et al. Randomized trial of peanut consumption in infants at risk for peanut allergy. N Engl J Med. 2015;372(9):803-813.

105. Du Toit G, et al. Effect of avoidance on peanut allergy after early peanut consumption. $N$ EnglJ Med. 2016;374(15):1435-1443.

106. Togias A, et al. Addendum guidelines for the prevention of peanut allergy in the United States: summary of the National Institute of Allergy and Infectious Diseases-sponsored expert panel. Pediatr Dermatol. 2017;34(1):5-12.

107. Keet CA, Wood RA, Matsui EC. Personal and parental nativity as risk factors for food sensitization. JAllergy Clin Immunol. 2012;129(1):169-175.e1.

108.Panjari M, et al. Nut allergy prevalence and differences between Asian-born children and Australianborn children of Asian descent: a state-wide survey of children at primary school entry in Victoria, Australia. Clin Exp Allergy. 2016;46(4):602-609.

109.Wegienka $\mathrm{G}$, et al. The associations between eczema and food and inhalant allergen-specific IgE vary between black and white children. JAllergy Clin Immunol Pract. 2018;6(1):292-294.e2.

110.Sharief S, Jariwala S, Kumar J, Muntner P, Melamed ML. Vitamin D levels and food and environmental allergies in the United States: results from the National Health and Nutrition Examination Survey 2005-2006. J Allergy Clin Immunol. 2011;127(5):1195-1202.

111. Mullins RJ, Clark S, Wiley V, Eyles D, Camargo CA. Neonatal vitamin D status and childhood peanut allergy: a pilot study. Ann Allergy Asthma Immunol. 2012;109(5):324-328.

112. Hypponen E, Berry DJ, Wjst M, Power C. Serum 25-hydroxyvitamin D and IgE - a significant but nonlinear relationship. Allergy. 2009;64(4):613-620.

113. Dellon ES, et al. Inverse association of esophageal eosinophilia with Helicobacter pylori based on analysis of a US pathology database. Gastroenterology. 2011;141(5):1586-1592.

114. Kusunoki T, et al. Birth order effect on childhood food allergy. Pediatr Allergy Immunol. 2012;23(3):250-254.

115. Du Toit G, et al. Identifying infants at high risk of peanut allergy: the Learning Early About Peanut Allergy (LEAP) screening study. J Allergy Clin Immunol. 2013;131(1):135-143.e1.

116. Alfven T, et al. Allergic diseases and atopic sensitization in children related to farming and anthroposophic lifestyle--the PARSIFAL study. Allergy. 2006;61(4):414-421.

117.Berni Canani R, Gilbert JA, Nagler CR. The role of the commensal microbiota in the regulation of tolerance to dietary allergens. Curr Opin Allergy Clin Immunol. 2015;15(3):243-249.

118. Sudo N, Sawamura S, Tanaka K, Aiba Y, Kubo C, Koga $Y$. The requirement of intestinal bacterial flora for the development of an IgE production system fully susceptible to oral tolerance induction. J Immunol. 1997;159(4):1739-1745.

119. Stefka AT, et al. Commensal bacteria protect against food allergen sensitization. Proc Natl Acad Sci U S A. 2014;111(36):13145-13150.

120. Azad MB, et al. Infant gut microbiota and food sensitization: associations in the first year of life. Clin Exp Allergy. 2015;45(3):632-643.

121. Berni Canani R, et al. Lactobacillus rhamnosus GG-supplemented formula expands butyrateproducing bacterial strains in food allergic infants. ISME J. 2016;10(3):742-750.

122. McKenzie C, Tan J, Macia L, Mackay CR. The nutrition-gut microbiome-physiology axis and allergic diseases. Immunol Rev. 2017;278(1):277-295.

123. Furusawa $Y$, et al. Commensal microbe-derived butyrate induces the differentiation of colonic regulatory T cells. Nature. 2013;504(7480):446-450.

124. Arpaia N, et al. Metabolites produced by commensal bacteria promote peripheral regulatory T-cell generation. Nature. 2013;504(7480):451-455.

125. Fukuda $\mathrm{S}$, et al. Bifidobacteria can protect from enteropathogenic infection through production of acetate. Nature. 2011;469(7331):543-547.

126. Trompette A, et al. Gut microbiota metabolism of dietary fiber influences allergic airway disease and hematopoiesis. Nat Med. 2014;20(2):159-166.

127. Macia L, et al. Metabolite-sensing receptors GPR43 and GPR109A facilitate dietary fibre-induced gut homeostasis through regulation of the inflammasome. Nat Commun. 2015;6:6734.

128. Barletta B, et al. Probiotic VSL\#3-induced TGFameliorates food allergy inflammation in a mouse model of peanut sensitization through the induction of regulatory $\mathrm{T}$ cells in the gut mucosa. Mol Nutr Food Res. 2013;57(12):2233-2244.

129. Atarashi K, et al. Treg induction by a rationally selected mixture of Clostridia strains from the human microbiota. Nature. 2013;500(7461):232-236.

130.Feehley T, et al. Healthy infants harbor intestinal bacteria that protect against food allergy [published online ahead of print January 14, 2019]. Nat Med.https://doi.org/10.1038/s41591-018-0324-z.

131. Pelucchi C, et al. Probiotics supplementation during pregnancy or infancy for the prevention of atopic dermatitis: a meta-analysis. Epidemiology. 2012;23(3):402-414.

132. Berni Canani R, et al. Effect of Lactobacillus GG on tolerance acquisition in infants with cow's milk allergy: a randomized trial. J Allergy Clin Immunol. 2012;129(2):580-582.e1.

133. Berni Canani R, et al. Extensively hydrolyzed casein formula containing Lactobacillus rhamnosus GG reduces the occurrence of other allergic manifestations in children with cow's milk allergy: 3-year randomized controlled trial. J Allergy Clin Immunol. 2017;139(6):1906-1913.e4.
134.Zmora N, et al. Personalized gut mucosal colonization resistance to empiric probiotics is associated with unique host and microbiome features. Cell. 2018;174(6):1388-1405.e21.

135. Suez J, et al. Post-antibiotic gut mucosal microbiome reconstitution is impaired by probiotics and improved by autologous FMT. Cell. 2018;174(6):1406-1423.e16.

136. Jones SM, Burks AW. Food allergy. $N$ Engl J Med. 2017;377(12):1168-1176.

137. Mondoulet L, Dioszeghy V, Ligouis M, Dhelft V, Dupont C, Benhamou PH. Epicutaneous immunotherapy on intact skin using a new delivery system in a murine model of allergy. Clin Exp Allergy. 2010;40(4):659-667.

138. Mondoulet L, et al. Epicutaneous immunotherapy (EPIT) blocks the allergic esophago-gastroenteropathy induced by sustained oral exposure to peanuts in sensitized mice. PLoS One. 2012;7(2):e31967.

139. Mondoulet L, et al. Gata3 hypermethylation Foxp3 hypomethylation are associated with sustained protection bystander effect following epicutaneous immunotherapy in peanut-sensitized mice [published online ahead of print May 19, 2018]. Allergy. https://doi.org/10.1111/all.13479.

140.Lucendo AJ, Arias A, Tenias JM. Relation between eosinophilic esophagitis and oral immunotherapy for food allergy: a systematic review with meta-analysis. Ann Allergy Asthma Immunol. 2014;113(6):624-629.

141. Echeverria-Zudaire LA, Fernandez-Fernandez S, Rayo-Fernandez A, Munoz-Archidona C, ChecaRodriguez R. Primary eosinophilic gastrointestinal disorders in children who have received food oral immunotherapy. Allergol Immunopathol (Madr). 2016;44(6):531-536.

142. Kawashima K, et al. Development of eosinophilic esophagitis following sublingual immunotherapy with cedar pollen extract: a case report. Allergol Int. 2018;67(4):515-517.

143. Miehlke S, Alpan O, Schroder S, Straumann A. Induction of eosinophilic esophagitis by sublingual pollen immunotherapy. Case Rep Gastroenterol. 2013;7(3):363-368.

144. Morais Silva P, Antunes J, Chambel M, Prates S, Leiria Pinto P. Diagnosis of eosinophilic esophagitis in an infant undergoing milk oral immunotherapy - a case report. Eur Ann Allergy Clin Immunol. 2014;46(4):154-156.

145. Noti M, et al. Thymic stromal lymphopoietinelicited basophil responses promote eosinophilic esophagitis. Nat Med. 2013;19(8):1005-1013.

146. Rosenberg CE, et al. Esophageal IgG4 levels correlate with histopathologic and transcriptomic features in eosinophilic esophagitis. Allergy. 2018;73(9):1892-1901.

147. Clayton F, et al. Eosinophilic esophagitis in adults is associated with IgG4 and not mediated by IgE. Gastroenterology. 2014;147(3):602-609.

148.Schuyler AJ, et al. Specific IgG4 antibodies to cow's milk proteins in pediatric patients with eosinophilic esophagitis. J Allergy Clin Immunol. 2018;142(1):139-148.e12.

149. Wright $\mathrm{BL}$, et al. Food-specific IgG4 is associated with eosinophilic esophagitis. JAllergy Clin Immunol. 2016;138(4):1190-1192.e3.

150. Lowe AJ, Leung DYM, Tang MLK, Su JC, Allen KJ. The skin as a target for prevention of the 
atopic march. Ann Allergy Asthma Immunol. 2018;120(2):145-151.

151. Horimukai K, et al. Application of moisturizer to neonates prevents development of atopic dermatitis. JAllergy Clin Immunol. 2014;134(4):824-830.e6.

152. Simpson EL, et al. Emollient enhancement of the skin barrier from birth offers effective atopic dermatitis prevention. JAllergy Clin Immunol. 2014;134(4):818-823.

153. Lowe AJ, et al. A randomized trial of a barrier lipid replacement strategy for the prevention of atopic dermatitis and allergic sensitization: the PEBBLES pilot study. Br J Dermatol. 2018;178(1):e19-e21.

154.Dellon ES, Liacouras CA. Advances in clinical management of eosinophilic esophagitis. Gastroenterology. 2014;147(6):1238-1254.

155. Bierme P, Nowak-Wegrzyn A, Caubet JC. Non-IgE-mediated gastrointestinal food allergies. Curr Opin Pediatr. 2017;29(6):697-703.

156.Abdel-Gadir A, et al. Oral immunotherapy with omalizumab reverses the Th2 cell-like programme of regulatory $\mathrm{T}$ cells and restores their function. Clin Exp Allergy. 2018;48(7):825-836.

157. Dantzer JA, Wood RA. The use of omalizumab in allergen immunotherapy. Clin Exp Allergy. 2018;48(3):232-240.

158. MacGinnitie AJ, et al. Omalizumab facilitates rapid oral desensitization for peanut allergy. J Allergy Clin Immunol. 2017;139(3):873-881.e8.

159. Frischmeyer-Guerrerio PA, et al. Mechanistic correlates of clinical responses to omalizumab in the setting of oral immunotherapy for milk allergy. JAllergy Clin Immunol. 2017;140(4):1043-1053.e8.

160. Andorf S, et al. Anti-IgE treatment with oral immunotherapy in multifood allergic participants: a double-blind, randomised, controlled trial. Lancet Gastroenterol Hepatol. 2018;3(2):85-94.

161. Rothenberg ME. Humanized anti-IL-5 antibody therapy. Cell. 2016;165(3):509.

162.Spergel JM, et al. Reslizumab in children and adolescents with eosinophilic esophagitis: results of a double-blind, randomized, placebocontrolled trial. JAllergy Clin Immunol. 2012;129(2):456-463.e1.

163. Assa'ad AH, et al. An antibody against IL-5 reduces numbers of esophageal intraepithelial eosinophils in children with eosinophilic esophagitis. Gastroenterology. 2011;141(5):1593-1604.
164. Otani IM, et al. Anti-IL-5 therapy reduces mast cell and IL-9 cell numbers in pediatric patients with eosinophilic esophagitis. JAllergy Clin Immunol. 2013;131(6):1576-1582.

165. Hirano I, et al. RPC4046, a monoclonal antibody against IL13, reduces histologic endoscopic activity in patients with eosinophilic esophagitis [published online ahead of print November 2, 2018]. Gastroenterology. https://doi.org/10.1053/ j.gastro.2018.10.051.

166. Rothenberg ME, et al. Intravenous anti-IL-13 mAb QAX576 for the treatment of eosinophilic esophagitis. J Allergy Clin Immunol. 2015;135(2):500-507.

167. Dellon ES, et al. Efficacy and safety of RPC4046, an anti-IL-13 monoclonal antibody, in patients with active eosinophilic esophagitis: analysis of the steroid-refractory subgroup from the HEROES study. Gastroenterology. 2018;154(6):S-244.

168. Hirano I, et al. Dupilumab efficacy and safety in adult patients with active eosinophilic esophagitis: a randomized double-blind placebocontrolled phase 2 trial. Paper presented at: World Congress of Gastroenterology at ACG 2017; October 16, 2017; Orlando, Florida, USA. https://www. eventscribe.com/2017/wcogacg2017/ajaxcalls/ PresentationInfo.asp?efp=S1lVTUxLQVozODMy\&PresentationID=325814\&rnd $=0.6944853$. Accessed February 26, 2019.

169.Zuo L, et al. IL-13 induces esophageal remodeling and gene expression by an eosinophil-independent, IL-13R $\alpha$ 2-inhibited pathway. J Immunol. 2010;185(1):660-669.

170. O'Shea KM, et al. Pathophysiology of eosinophilic esophagitis. Gastroenterology. 2018;154(2):333-345.

171. Corren J, et al. Tezepelumab in adults with uncontrolled asthma. $N$ Engl J Med. 2017;377(10):936-946.

172. Galand C, et al. IL-33 promotes food anaphylaxis in epicutaneously sensitized mice by targeting mast cells. J Allergy Clin Immunol. 2016;138(5):1356-1366

173. AnaptysBio Announces Positive Top-Line Proofof-Concept Data For ANBO20 In Moderate-toSevere Baseline Adult Peanut Allergy Patients [press release].San Diego, CA: Globe Newswire March 26, 2018

174. Blanchard C, et al. IL-13 involvement in eosinophilic esophagitis: transcriptome analysis and reversibility with glucocorticoids. JAllergy Clin Immunol. 2007;120(6):1292-1300.

175. Travers J, Rothenberg ME. Eosinophils in mucosal immune responses. Mucosal Immunol. 2015;8(3):464-475

176. Caubet JC, Bencharitiwong R, Ross A, Sampson HA, Berin MC, Nowak-Węgrzyn A. Humoral and cellular responses to casein in patients with food protein-induced enterocolitis to cow's milk. JAllergy Clin Immunol. 2017;139(2):572-583.

177. Morita H, et al. Antigen-specific T-cell responses in patients with non-IgE-mediated gastrointestinal food allergy are predominantly skewed to $\mathrm{T}(\mathrm{H}) 2$. JAllergy Clin Immunol. 2013;131(2):590-592.e1.

178. Kimura M, et al. Cytokine profile after oral food challenge in infants with food proteininduced enterocolitis syndrome. Allergol Int. 2017;66(3):452-457.

179. Cherian S, Varshney P. Food Protein-Induced Enterocolitis Syndrome (FPIES): review of recent guidelines. Curr Allergy Asthma Rep. 2018;18(4):28.

180. Leonard SA. Non-IgE-mediated adverse food reactions. Curr Allergy Asthma Rep. 2017;17(12):84.

181. Stamnaes J, Sollid LM. Celiac disease: autoimmunity in response to food antigen. Semin Immunol. 2015;27(5):343-352.

182.Stamnaes J, Sollid LM. Celiac disease: autoimmunity in response to food antigen. Semin Immunol. 2015;27(5):343-352.

183. Oettgen HC. Regulation of the IgE isotype switch: new insights on cytokine signals and the functions of epsilon germline transcripts. Curr Opin Immunol. 2000;12(6):618-623

184.Shik D, Tomar S, Lee JB, Chen CY, Smith A, Wang YH. IL-9-producing cells in the development of IgE-mediated food allergy. Semin Immunopathol. 2017;39(1):69-77.

185. Kubo M. Mast cells and basophils in allergic inflammation. Curr Opin Immunol. 2018;54:74-79.

186. Gutierrez-Achury J, et al. Fine mapping in the MHC region accounts for $18 \%$ additional genetic risk for celiac disease. Nat Genet. 2015;47(6):577-578.

187. Goswami R, Blazquez AB, Kosoy R, Rahman A, Nowak-Węgrzyn A, Berin MC. Systemic innate immune activation in food protein-induced enterocolitis syndrome. J Allergy Clin Immunol. 2017;139(6):1885-1896.e9. 